CLINICAL STUDY

\title{
Mortality and GH deficiency: a nationwide study
}

Kirstine Stochholm, Claus Højbjerg Gravholt, Torben Laursen ${ }^{1}$, Peter Laurberg ${ }^{2}$, Marianne Andersen ${ }^{3}$, Lars Østergaard Kristensen ${ }^{4}$, Ulla Feldt-Rasmussen ${ }^{5}$, Jens Sandahl Christiansen, Morten Frydenberg ${ }^{6}$ and $^{2}$ Anders Green ${ }^{7,8}$

Medical Department M (Endocrinology and Diabetes), Aarhus University Hospital, Aarhus Sygehus, NBG, DK-8000 Aarhus C, Denmark, ${ }^{1}$ Department of Pharmacology, University of Aarhus, 8000 Aarhus C, Denmark, ${ }^{2}$ Department of Endocrinology, Aalborg University Hospital, 9000 Aalborg, Denmark, ${ }^{3}$ Department of Endocrinology, Odense University Hospital, 5000 Odense C, Denmark, ${ }^{4}$ Department of Endocrinology, Herlev University Hospital, 2730 Herlev, Denmark, ${ }^{5}$ Department of Endocrinology PE, Rigshospitalet, 2100 Copenhagen, Denmark, ${ }^{6}$ Department of Biostatistics, University of Aarhus, 8000 Aarhus C, Denmark, ${ }^{7}$ Department of Applied Research and HTA, Odense University Hospital, 5000 Odense C, Denmark and ${ }^{8}$ Institute of Public Health, University of Southern Denmark, 5000 Odense C, Denmark

(Correspondence should be addressed to K Stochholm; Email: stochholm@dadlnet.dk)

\begin{abstract}
Objective: To estimate the mortality in Denmark in patients suffering from GH deficiency (GHD). Design: Mortality was analyzed in 1794 GHD patients and 8014 controls matched on age and gender. All records in GHD patients were studied and additional morbidity noted. Patients were divided into childhood onset (CO) and adult onset (AO), discriminated by an age cutoff below or above 18 years at onset of GHD. Method: Data on death were identified in national registries. Sex- and cause-specific mortalities were identified in $\mathrm{CO}$ and $\mathrm{AO}$ GHD when compared with controls.

Results: Mortality was increased in $\mathrm{CO}$ and $\mathrm{AO}$ GHD in both genders, when compared with controls. The hazard ratio (HR) for CO males was 8.3 (95\% confidence interval (CI) 4.5-15.1) and for females 9.4 (CI 4.6-19.4). For AO males, HR was 1.9 (CI 1.7-2.2) and for females 3.4 (CI 2.9-4.0). We found a significantly higher $\mathrm{HR}$ in $\mathrm{AO}$ females versus $\mathrm{AO}$ males, both compared with controls $(P<0.001)$. In AO, mortality was increased due to cancer in all subgroups, due to circulatory diseases in all age groups for females and for males in the oldest age group. For CO, the increased mortality was due to cancer. Conclusions: We found a significantly increased mortality in GHD patients when compared with controls, possibly due to their hypopituitary status. Mortality was increased in AO female patients when compared with males. For CO and AO GHD, different causes of significantly increased mortality were identified.
\end{abstract}

European Journal of Endocrinology 157 9-18

\section{Introduction}

Several studies examined mortality in hypopituitary patients and found an increased mortality when compared with the background population (1-4). Some hypothesize that the increased mortality is due to growth hormone $(\mathrm{GH})$ deficiency (GHD; $(1,3)$ ), while others hypothesize that increased mortality is due to gonadotropin deficiency and lack of sex hormone substitution in female hypogonadism (4). Excess mortality is caused by cardiovascular, cerebrovascular, and respiratory diseases, whereas the excess mortality caused by cancer is disputed. One study reported normal mortality in 289 GH-treated GHD patients and increased mortality in a relatively older group of 1411 hypopituitary patients, both compared with the background population (5). An increased mortality in patients with pituitary adenomas was identified, especially due to cardiovascular deaths (6).

A small study found decreased survival of patients with hereditary isolated GHD compared with unaffected siblings and a geographically and age-matched group
(7). Normal mortality was found in GHD children treated with human pituitary GH (hGH) during 19761992 (8). Significantly increased cancer mortality was found in children and adolescents treated with hGH during 1959-1985 (9). However, the number of cases was small and related to high-risk patients (9). Hypopituitary patients comprise a heterogeneous group as regards underlying disease and its treatment, as well as the degree of hypopituitarism. Men and women may differ with respect to the cause of disease, and substitution with sex steroids and GH (10).

In this nationwide study, we focused on mortality in patients suffering from GHD, a diagnosis verified by a thorough examination of individual records from patients with an increased risk of GHD. In addition, we investigated the impact of additional morbidity on the mortality of these patients. We used a combined approach of the study of all patient files at the local hospital, the construction of a matched control group, and subsequent extraction of data on mortality from the causes of death registry (CDR). 


\section{Subjects and methods}

To identify all cases of possible GHD in Denmark, we used the unique Danish registries. Three registries identified the primary cohort: the Cancer Registry (CR), which registers patients in Danish hospitals with a cancer diagnosis; the National Patients Registry (NPR), which registers all in-patients, and since 1995 all out-patients; and the CDR, which registers causes of death in all deceased Danes.

In CR, we applied for the following topography: the pituitary gland, the ductus craniopharyngei and the pineal gland, and both benign and malignant morphology. In NPR, we searched for all hospital activities coded with one or more of 31 diagnoses, using International Classification of Diseases 8th edition (ICD-8) and ICD-10, with an increased risk of GHD. For details, see (11). From CDR, we identified all cases with specific hypopituitary diagnoses. For all registries, the hospital in which the case was diagnosed was recorded with a code uniquely assigned to each hospital in Denmark. The cases from CR, NPR, and CDR all had an increased $a$ priori risk of having GHD. To identify the patients with GHD, we visited all departments, including psychiatric wards, in Denmark where the CPR numbers had been registered. All departments with registrations gave permission to read the records.

Criteria for GHD diagnosis were chosen based on published guidelines $(12,13)$ with modifications (14-16); see Table 1. If necessary, two or more departments were visited in order to find relevant and sufficient data about each case. All records were studied first at the hospitals with specialized departments (i.e. pediatric, neurosurgical, or endocrine departments), thereafter at hospitals without specialized departments. It is important to stress that the diagnosis of GHD was only applied when the clinical context was relevant. We identified 9131 possible GHD cases and verified the diagnosis of GHD by studying their individual records. In total, 2205 patients fulfilled our criteria of GHD.

In describing the cohort, the following dates are important: (1) date of onset represents the estimated date the patient became GH deficient; (2) date of sufficient information represents the date when the date of onset was notified in a record; (3) date of registration represents the first date when the patient is noted in any register and (4) for each patient, date of entry of GHD was defined as (1) the date of first registration in the registry or (2) the date of sufficient information, whichever came last. It is necessary to use the latest date since patients must be both registered to enter the primary cohort of possible cases, and the record must contain sufficient information to ensure a correct diagnosis of GHD. The entry date is considered as the incident date and does not necessarily represent a diagnosis at the hospital, since only some of the patients were formally tested for GHD at any department. The date of onset is not used for the calculation of start of risk time, and rather used to give a rough estimate of the difference between date of entry and date of onset, defined as 'delay'. Delay represents the period in which patients had GHD without contributing with follow-up time. The date of entry occurred during 1980-1999 in 1823 patients.

The patients were divided into four subgroups according to gender and age on the date of onset: childhood onset ( $\mathrm{CO}$; younger than 18 years) and adult onset (AO; 18 years or more). To describe the impact of age at entry on mortality, we divided patients with AO into four age groups: $<45,45-54,55-64$, and 65 years or more at entry.

To obtain controls, we used the Central Office of Civil Registration (OCR). Here, vital statistical information including birth, death, and emigration of Danish citizens is centralized using the unique Central Person Number. On August 6, 2004, OCR matched the 1823 patients with up to 5 controls each. The controls were matched on gender and age (month and year of birth), and were alive on the date of entry. For 29 patients, no controls were identified; they were omitted from all calculations. We received 8014 controls for 1794 patients. We received information from OCR about date of death, emigration, or loss of follow-up. For total mortality, we analyzed data on 1794 patients (644 deaths) and 8014 controls (1700 deaths). All were censored on August 6, 2004 or on date of exit, whichever came first.

The causes of death were identified in the CDR. CDR was established in 1970 and updated until December 31, 2001. Thus, no information on the cause-specific mortality is available after this date; hence, all persons were censored on December 31, 2001 or on date of exit, whichever came first, regardless of information on exit after this date. CDR used ICD-8 until 1993, hereafter ICD10. We translated ICD-8 diagnoses to ICD-10. For causespecific mortality, data were available and analyzed on 1794 patients (565 deaths) and 8014 controls (1372 deaths). Cause-specific mortality hazard ratios (HR) were calculated for each of the 19 chapters in ICD-10, and one chapter for no code. The age- and gender-specific analyses were performed on chapters with at least 20 and 80 deaths for $\mathrm{CO}$ and $\mathrm{AO}$ respectively, corresponding to a hypothetical and relevant minimum of ten deaths in each stratum after division.

Deficiencies of the other pituitary axes were defined as follows: adrenocorticotropin (ACTH), an insufficient response to metyrapone or synacthen; thyrotropin (TSH), blood sample combined with a clinical decision of deficiency; follicle-stimulating hormone/luteinizing hormone (FSH/LH), blood sample combined with a clinical decision of deficiency or a clinical definition of deficiency; and vasopressin (anti-diuretic hormone, $\mathrm{ADH}$ ), a positive thirst test or clinical suspicion of deficiency combined with successful medical treatment for more than 3 months. The patients were defined as deficient on the relevant axis if one of the above was deficient at any stage, or they were substituted on the axis. 
Criteria for GHD diagnosis

Criteria for each test:

Accepted tests

ACTH

$\mathrm{FSH} / \mathrm{LH}$

TSH

$\mathrm{ADH}$

Growth retardation

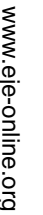

Table 1 Criteria for the diagnosis of growth hormone deficiency (GHD) divided into subgroups, childhood onset and adult onset.
Childhood onset ( $<18$ years of age at onset)

Two positive stimulation tests, or one positive stimulation test and IGF-I<2 S.D., or one positive stimulation test and documented insufficiency of one hormone, or one positive stimulation test and pituitary irradiation, or one positive stimulation test and pituitary pathology (CT or MRI scan), or one positive stimulation test and verified genetic defect resulting in GHD, or one positive stimulation test and growth retardation, or growth retardation and documented insufficiency of one hormone, or growth retardation and pituitary insufficiency of one hormone, or growth retardation and pituitary irradiation, or operation on the pituitary and documented insuffi-
ciency of one hormone, or operation on the pituitary and pituitary irradiation, or pituitary irradiation and documented insufficiency of one hormone, or relevant clinical diagnosis ${ }^{a}$

Insulin tolerance test (ITT), arginine and growth hormone-releasing hormone (GHRH), arginine, clonidin, glucagon, L-dopa, and heat exposure

Synachten or insulin tolerance test (ITT) $<550 \mathrm{nmol} / \mathrm{l}$ after $30 \mathrm{~min}$. If department had a well-defined and different cutoff, this value was used. Metyrapone test followed by a clinical interpretation of insufficiency blood samples followed by a clinical interpretation of insufficiency

FSH/LH below relevant reference females: estrogen below relevant reference followed by clinical interpretation of insufficiency. Amenorrhea followed by clinical interpretation of insufficiency. Males: testosterone below relevant reference. Secondary sexual de

$T_{4}$ below relevant reference. $T_{4}$ within reference followed by a clinical interpretation of insufficiency.

Insufficient response during water deprivation test. Clinical interpre-

tation of insufficiency combined with successful medical treatment for more than 3 months

Height $>3$ S.D. below mean; height $>1.5$ s.D. below expected parental Irrelevant

height; height $>2$ s.D. below mean and reduced by more than 0.5 S.D.

during 1 year among children more than 2 years of age; change in

height $>2$ s. below mean for 1 year; change in height $>1.5$.

below mean for 2 years

Same

\section{Same}

Same
Adult onset (18 years of age or more at onset)

Two positive stimulation tests, or one positive stimulation test and documented insufficiency of one hormone, or IGF-I <2 S.D. and documented insufficiency of one hormone, or operation on the pituitary and pituitary irradiation, or operation on the pituitary and documented insufficiency of one hormone, or two pituitary

operations, or documented insufficiency of two hormones, or pituitary pathology (CT or MRI scan) and documented insufficiency of one hormone, or pituitary irradiation ( $>5$ years) and documented insufficiency of one hormone, or relevant clinical diagnosis ${ }^{\mathrm{a}}$

ITT, arginine and GHRH, pyridostigmin and $\mathrm{GHRH}$, arginine, glucagon and heat exposure

Same, and LHRH test followed by a clinical interpretation of insufficiency. FSH/LH below relevant reference (postmenopausal) followed by a clinical interpretation of insufficiency. Loss of libido followed by a clinical interpretation of insufficiency

aHistory of pituitary apoplexy, craniopharyngeoma, empty sella, Sheehan's syndrome, trauma, pituitary bleeding and GHD combined with history of medical substitution. 
The study was approved by the Danish Data Protection Agency, the Research Ethics Committee, and Doctors' Counsel in the Danish National Board of Health.

\section{Statistical analysis}

The characteristics of the patients with $\mathrm{CO}$ and AO GHD were compared using the $\chi^{2}$-test. Kaplan-Meier survival estimates were constructed from entry until exit from the cohort, with log-rank analysis. HRs were calculated using Cox regression analysis with stratification, using each GHD patient and the matched controls as a stratum. Thus, comparisons were adjusted for gender, age, and calendar time. Changes in mortality with changes in age were analyzed using Cox regression applying age at entry as a linear variable. Cause-specific mortality HRs were calculated for each of the 20 chapters. Risk time started on the date of entry in all analyses apart from the analysis on GH-treated patients. Here, risk time started the date GH therapy was initiated. Mortality in the patient cohort was analyzed using Cox regression stratified by age at entry (5-year intervals). All results are shown with 95\% confidence intervals (CIs). $P<0.05$ was considered significant. We made no formal corrections for multiple comparisons. Stata 8.2 for Windows (Stata Corp., College Station, TX, USA) was used for all calculations.

\section{Results}

\section{Patients}

Characteristics of the patients are given in Table 2. Approximately 30\% CO and 20\% AO GHD patients were irradiated. The distribution of irradiation, surgery, additional deficits, chemotherapy, and GH treatment were significantly different in $\mathrm{CO}$ patients when compared with AO patients. Significantly more hypogonadal AO males were substituted with sex steroids when compared with females (all $<55$ years of age at entry). More than $90 \%$ of patients with ACTH-, ADH-, and/or TSH-deficiency were substituted on the relevant axis.

For the following analyses, it is important to note that mortality data are compared with controls, unless specified differently.

\section{Total mortality}

We identified a significantly increased mortality in CO and AO GHD for both genders (Table 3). There was no difference in mortality between males and females in CO GHD $(P=0.83)$, whereas in $\mathrm{AO}$ GHD, the hazard in females was significantly higher than in males $(P<$ $0.001)$. Survival is shown in Fig. 1; 50\% survival was 15.8 (CI 14.8-18.4) years after entry for AO males and

Table 2 Characteristics of the patients with growth hormone deficiency (GHD). Patients were divided into childhood- and adult-onset GHD, discriminated by an age cutoff below or above 18 years at onset. Onset is when the patients became GHD, entry is when follow-up begins, and delay is the difference between entry and onset. Potential follow-up is calculated as follow-up without any exits before censoring at the end of the study. Factual follow-up includes exits and emigrations in the calculation.

\begin{tabular}{|c|c|c|c|c|}
\hline & $\begin{array}{l}\text { Childhood-onset } \\
\text { males }\end{array}$ & $\begin{array}{l}\text { Childhood-onset } \\
\text { females }\end{array}$ & $\begin{array}{l}\text { Adult-onset } \\
\text { males }\end{array}$ & $\begin{array}{l}\text { Adult-onset } \\
\text { females }\end{array}$ \\
\hline Number of patients & 299 & 187 & 732 & 576 \\
\hline Number of deceased patients $1980-2001^{a}$ & 30 & 22 & 279 & 234 \\
\hline Number of deceased patients $1980-2004^{b}$ & 34 & 23 & 320 & 267 \\
\hline Median age (range) at onset (years) & $8.9(0.0-18.0)$ & $8.3(0.0-18.0)$ & $52.4(18.1-91.3)$ & $48.8(18.0-87.6)$ \\
\hline Median age (range) at entry (years) & $13.5(0.1-77.0)$ & $12.9(0.1-78.8)$ & $57.2(18.1-91.3)$ & $55.8(18.5-87.7)$ \\
\hline Median delay (range; years) & $1.0(0.0-61.0)$ & $1.2(0.0-62.4)$ & $0.2(0.0-48.8)$ & $0.3(0.0-56.2)$ \\
\hline Median potential follow-up (range; years) & $12.8(4.7-24.4)$ & $12.8(4.7-24.6)$ & $13.2(4.6-24.5)$ & $13.8(4.6-24.6)$ \\
\hline Median factual follow-up (range; years) & $11.6(0.0-24.2)$ & $11.6(0.0-24.6)$ & $8.6(0.0-24.5)$ & $8.6(0.0-24.5)$ \\
\hline Percentage diagnosed $\mathrm{GHD}^{\mathrm{c}, \mathrm{d}}$ & 73.3 & 73.8 & 30.0 & 29.7 \\
\hline Irradiation (\%) ${ }^{\mathrm{d}}$ & 30.8 & 28.3 & 19.8 & 21.0 \\
\hline Surgery $(\%)^{d^{\prime}}$ & 32.1 & 37.4 & 70.9 & 67.7 \\
\hline No other deficits (\%) ${ }^{\mathrm{d}}$ & 34.1 & 35.3 & 6.3 & 9.2 \\
\hline One to two additional deficits (\%) & 36.8 & 32.1 & 33.2 & 46.5 \\
\hline Three to four additional deficits (\%) & 29.1 & 32.6 & 60.5 & 44.3 \\
\hline Treatment with chemotherapy (\%) d & 10.4 & 7.5 & 1.8 & 1.6 \\
\hline Substitution on $\mathrm{GH}$ axis (\%) & 77.3 & 74.9 & 24.9 & 22.2 \\
\hline \multicolumn{5}{|l|}{ Number of patients deficient (substituted) } \\
\hline $\mathrm{ADH}$ axis & $54(53)$ & $35(32)$ & $110(101)$ & $113(104)$ \\
\hline TSH axis & 135 (128) & $87(87)$ & $538(506)$ & 395 (370) \\
\hline ACTH axis & 115 (109) & $79(73)$ & $581(559)$ & 437 (425) \\
\hline $\mathrm{FSH} / \mathrm{LH}$ axis $^{\mathrm{e}}$ & $147(121)$ & $91(75)$ & $268(241)$ & $198(150)$ \\
\hline
\end{tabular}


Table 3 Total mortality in patients with growth hormone deficiency (GHD), compared with controls and within the patient cohort. Patients were divided by gender and into childhood- and adult-onset GHD, discriminated by an age cutoff below or above 18 years at onset.

\begin{tabular}{lll}
\hline Hazard ratio & $\begin{array}{c}\text { Childhood } \\
\text { onset }\end{array}$ & Adult onset \\
\hline GHD males versus controls $^{\mathrm{a}}$ & $8.3(4.5-15.1)$ & $1.9(1.7-2.2)$ \\
GHD females versus controls $^{\mathrm{a}}$ & $9.4(4.6-19.4)$ & $3.4(2.9-4.0)^{\mathrm{b}}$ \\
GHD females versus males $^{\mathrm{b}}$ & $1.0(0.6-1.8)$ & $1.1(0.9-1.3)$
\end{tabular}

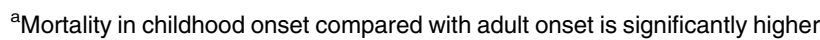
$(P<0.05)$.

${ }^{\mathrm{b}}$ Mortality in females versus controls is significantly higher than in males $(P<0.001)$
21.1 (CI 19.9-22.7) years for controls. Similarly, for AO females, 50\% survival was 14.0 (CI 12.9-16.1) years after entry for patients and more than 23.8 years for controls.

\section{Age-specific mortality}

For both the genders, we found a significantly increased hazard in all age groups (Fig. 2), and it was significantly higher in females when compared with males. HR significantly decreased with increasing age in both males $(P<0.05)$ and females $(P<0.001)$.
Childhood onset, males

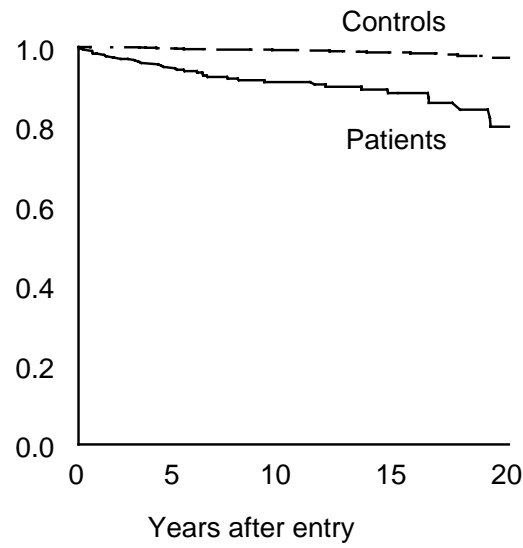

Number of patients/controls

$\begin{array}{rrrrr}299 & 269 & 179 & 97 & 32 \\ 1332 & 1279 & 881 & 491 & 178\end{array}$

Adult onset, males

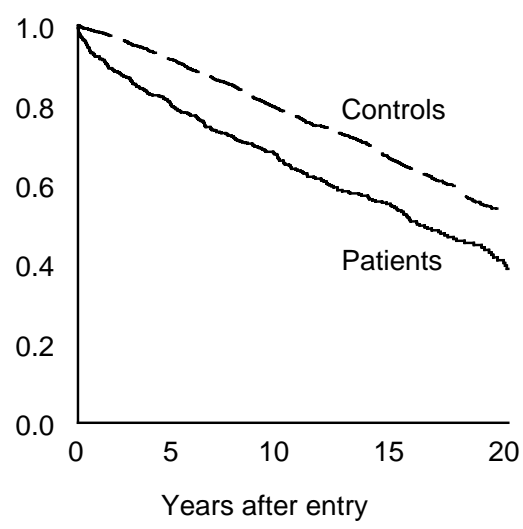

Number of patients/controls

$\begin{array}{rrrrr}732 & 550 & 302 & 160 & 54 \\ 3200 & 2748 & 1613 & 857 & 338\end{array}$

Childhood onset, females

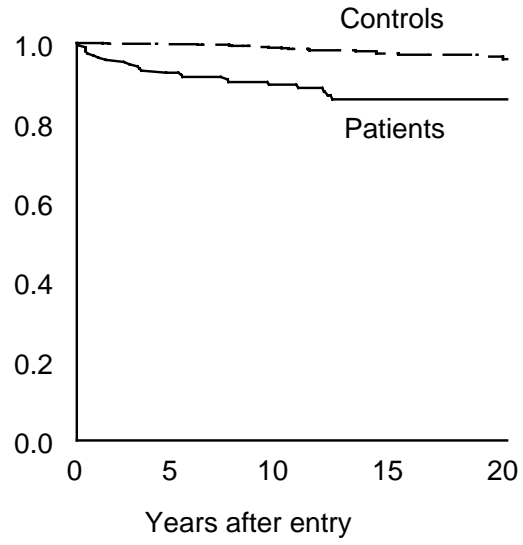

$\begin{array}{rrrrr}187 & 169 & 117 & 60 & 25 \\ 872 & 848 & 597 & 334 & 159\end{array}$

Adult onset, females

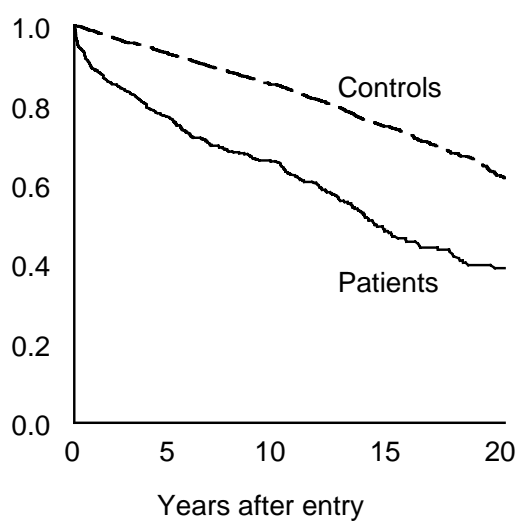

$\begin{array}{rrrrr}576 & 412 & 244 & 106 & 48 \\ 2610 & 2321 & 1526 & 836 & 387\end{array}$

Figure 1 Kaplan-Meier survival graphs by childhood- and adult-onset growth hormone deficiency discriminated by an age cutoff below or above 18 years at onset. Time at risk is calculated from the date of entry. The mortality was significantly higher in patients when compared with controls (log rank, $P<0.0001)$. Dashed lines, controls; solid lines, patients. Number of patients and number of controls at $0,5,10,15$, and 20 years after entry are indicated below the figure. 


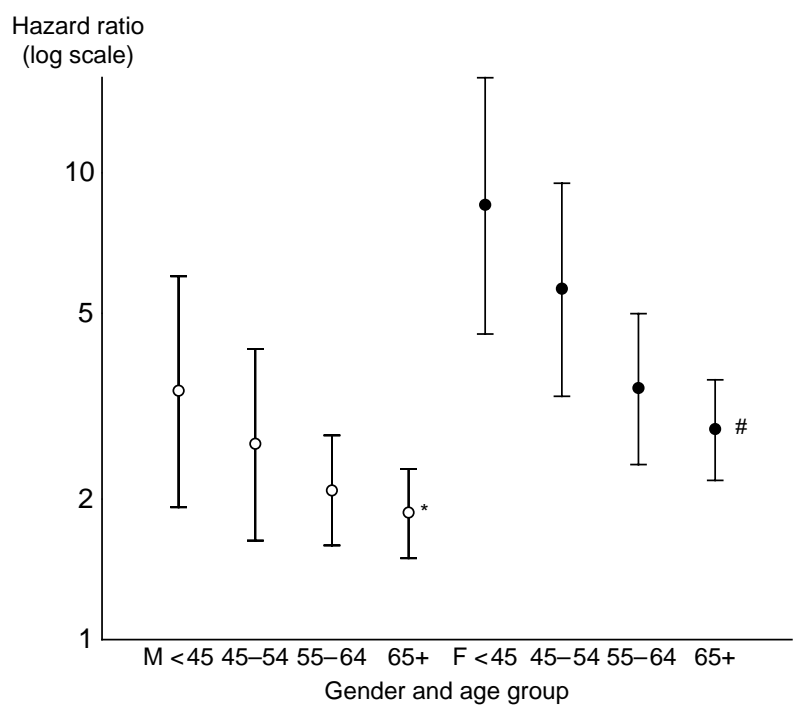

Figure 2 Hazard ratios of total mortality in adult-onset GHD, 1980-2004, subdivided into four age groups according to age at entry and gender. Open circles, males; black circles, females. Mortality is decreasing with increasing age at entry ${ }^{\star} P<0.05$ and ${ }^{\#} P<$ 0.001 .

\section{Cause-specific mortality}

Table 4 shows $\mathrm{HR}$ for $\mathrm{CO}$ and $\mathrm{AO}$ GHD divided into 19 chapters as defined in ICD-10 and one chapter for unknown registration. HR was significantly increased for cancer among CO GHD. Divided by gender, this HR was 31.1 (CI 9.2-104.4) for males and 11.7 (CI 4.1-33.2) for females.

Among AO GHD, HR was increased for cancer, endocrine diseases, circulatory system, digestive system, in the unspecific group of symptoms and signs not elsewhere classified, and in trauma. We divided data according to gender and into four age groups according to age at entry (Table 5). Mortality from circulatory diseases in males was significantly higher in the older age group, increasing insignificantly with increasing age $(P=0.13)$, whereas HR for females was significantly elevated in all age groups and decreasing significantly with increasing age $(P<0.05)$. In the two youngest age groups, females had significantly higher HR when compared with males $(P<0.05)$, whereas there was no statistical difference in the $55-64$ years $(P=0.07)$ and $65+$ years $(P=0.13)$ groups. We divided the circulatory mortality into cerebrovascular and cardiovascular mortality (Table 5).

Table 4 Hazard ratios of childhood- and adult-onset growth hormone deficiency describing, in detail, mortality divided into 19 chapters from International Classification of Diseases (ICD)-8 and ICD-10 and one for no code, 1980-2001. Childhood- and adult-onset were discriminated by an age cutoff below or above 18 years at onset. All chapters that contained no deaths were omitted from the table (diseases of the blood and blood-forming organs; diseases of the eye; diseases of the ear; pregnancy, childbirth, and puerperium; and conditions originating in perinatal period). Significant hazard ratios (HRs) are given in bold face.

\begin{tabular}{|c|c|c|c|c|c|c|}
\hline & ICD-10 & ICD-8 & $\begin{array}{l}\text { Childhood } \\
\text { onset num- } \\
\text { ber of } \\
\text { deaths } \\
\text { (patients/ } \\
\text { controls) }\end{array}$ & $\begin{array}{l}\text { Childhood } \\
\text { onset hazard } \\
\text { ratio }\end{array}$ & $\begin{array}{c}\text { Adult onset } \\
\text { number of } \\
\text { deaths } \\
\text { (patients/ } \\
\text { controls) }\end{array}$ & $\begin{array}{l}\text { Adult onset } \\
\text { hazard ratio }\end{array}$ \\
\hline Infections and parasitic diseases & A00-A99 B00-B99 & $000.00-136.99$ & $0 / 1$ & $-^{a}$ & $3 / 2$ & $-^{a}$ \\
\hline Cancer & C00-C97 D00-D48 & $140.00-239.99$ & $34 / 11$ & $19.0(8.8-41.2)$ & $197 / 405$ & $3.5(2.9-4.3)$ \\
\hline $\begin{array}{l}\text { Endocrine, nutritional, and } \\
\text { metabolic diseases }\end{array}$ & E00-E90 & $240.00-279.99$ & $2 / 3$ & $3.3(0.5-24.2)$ & $55 / 36$ & $9.8(5.9-16.4)$ \\
\hline Mental and behavioral diseases & F00-F99 & $290.00-315.99$ & $0 / 1$ & $-^{a}$ & $2 / 23$ & $1.1(0.2-5.3)$ \\
\hline Diseases of the nervous system & G00-G99 H00-H95 & $320.00-358.99$ & $2 / 0$ & $-^{a}$ & $5 / 15$ & $2.1(0.7-6.5)$ \\
\hline $\begin{array}{l}\text { Diseases of the circulatory } \\
\text { system }\end{array}$ & $100-199$ & $390.00-458.99$ & $3 / 2$ & $5.5(0.9-33.5)$ & $158 / 549$ & $1.9(1.5-2.3)$ \\
\hline $\begin{array}{l}\text { Diseases of the respiratory } \\
\text { system }\end{array}$ & J00-J99 & $460.00-519.99$ & $2 / 1$ & $-{ }^{\mathrm{a}}$ & $21 / 115$ & $1.0(0.6-1.7)$ \\
\hline Diseases of the digestive system & K00-K93 & $520.00-577.99$ & $1 / 0$ & $-^{a}$ & $15 / 36$ & $3.3(1.6-6.9)$ \\
\hline $\begin{array}{l}\text { Diseases of the skin and s.c. } \\
\text { tissue }\end{array}$ & L00-L99 & $680.00-709.99$ & $0 / 0$ & $-^{a}$ & $0 / 1$ & $-^{a}$ \\
\hline $\begin{array}{l}\text { Diseases of the musculoskeletal } \\
\text { system and connective tissue }\end{array}$ & M00-M99 & 710.00-738.99 & $0 / 0$ & $--^{a}$ & $2 / 4$ & $8.5(0.8-95.3)$ \\
\hline $\begin{array}{l}\text { Diseases of the genitourinary } \\
\text { system }\end{array}$ & N00-N99 & $580.00-629.99$ & $0 / 0$ & $-^{a}$ & $4 / 23$ & $0.8(0.2-2.9)$ \\
\hline $\begin{array}{l}\text { Congenital malformations, } \\
\text { deformations, and } \\
\text { chromosomal abnormalities }\end{array}$ & Q00-Q99 & $740.00-759.99$ & $3 / 0$ & $--^{a}$ & $0 / 1$ & $-{ }^{\mathrm{a}}$ \\
\hline $\begin{array}{l}\text { Symptoms and signs not } \\
\text { elsewhere classified }\end{array}$ & Ro0-R99 & 780.00-796.99 & $4 / 3$ & $7.5(1.3-41.4)$ & $30 / 67$ & $3.0(1.8-5.0)$ \\
\hline $\begin{array}{l}\text { Trauma } \\
\text { No code in the causes of deaths } \\
\text { registry }\end{array}$ & VW X Y & 800.00-999.99 & $\begin{array}{l}1 / 6 \\
0 / 1\end{array}$ & $\begin{array}{c}0.9 \underset{-a}{(0.1-7.9)} \\
-{ }^{a}\end{array}$ & $\begin{array}{c}21 / 58 \\
0 / 8\end{array}$ & $\underset{{ }^{a}}{2.0}(1.1-3.5)$ \\
\hline
\end{tabular}

${ }^{a}$ Due to few informative strata, statistical analysis was not possible. 
Table 5 Hazard ratios for males and females with adult-onset growth hormone deficiency (GHD) compared with the background population, divided into the chapters which had more than 80 deaths and were significantly increased in Table 4 . Adult onset was defined by onset of GHD after 18 years of age. The patients are subdivided into four age groups: <45 years, 45-54 years, 55-64 years, and 65+ years at entry. Significant hazard ratios (HRs) are given in bold face.

\begin{tabular}{|c|c|c|c|c|c|c|c|c|c|c|}
\hline & \multicolumn{2}{|c|}{$<\mathbf{4 5}$ years } & \multicolumn{2}{|c|}{$45-54$ years } & \multicolumn{2}{|c|}{$55-64$ years } & \multicolumn{2}{|c|}{$65+$ years } & \multicolumn{2}{|c|}{ Total } \\
\hline & $\begin{array}{l}\text { Number of } \\
\text { deaths } \\
\text { (patients/ } \\
\text { controls) }\end{array}$ & Hazard ratio & $\begin{array}{l}\text { Number of } \\
\text { deaths } \\
\text { (patients/ } \\
\text { controls) }\end{array}$ & Hazard ratio & $\begin{array}{l}\text { Number of } \\
\text { deaths } \\
\text { (patients/ } \\
\text { controls) }\end{array}$ & Hazard ratio & $\begin{array}{l}\text { Number of } \\
\text { deaths } \\
\text { (patients/ } \\
\text { controls) }\end{array}$ & Hazard ratio & $\begin{array}{l}\text { Number of } \\
\text { deaths } \\
\text { (patients/ } \\
\text { controls) }\end{array}$ & Hazard ratio \\
\hline \multicolumn{11}{|l|}{ Adult onset males } \\
\hline Cancer & $14 / 7$ & $12.2(4.3-34.0)$ & $20 / 18$ & $7.2(3.5-14.8)$ & $40 / 92$ & $2.8(1.9-4.2)$ & $38 / 122$ & $2.3(1.5-3.5)$ & $112 / 239$ & $3.3(2.5-4.3)$ \\
\hline $\begin{array}{l}\text { Endocrine, nutritional, } \\
\text { and metabolic diseases }\end{array}$ & $1 / 1$ & $4.5(0.3-71.8)$ & $2 / 1$ & $-^{\mathrm{a}}$ & $7 / 5$ & $5.8(1.8-18.4)$ & $10 / 8$ & $7.7(2.3-25.2)$ & $20 / 15$ & $7.3(3.4-15.8)$ \\
\hline $\begin{array}{l}\text { Diseases of the } \\
\text { circulatory system: }\end{array}$ & $1 / 7$ & $0.7(0.1-5.4)$ & $4 / 29$ & $0.6(0.2-1.9)$ & $24 / 95$ & $1.5(0.9-2.4)$ & $60 / 203$ & $1.6(1.1-2.3)$ & $89 / 334$ & $1.5(1.1-1.9)$ \\
\hline $\begin{array}{l}\text { Cerebrovascular } \\
\text { diseases }\end{array}$ & $1 / 0$ & $-^{a}$ & $2 / 6$ & $1.1(0.1-10.6)$ & $6 / 13$ & $4.9(1.5-16.2)$ & $7 / 38$ & $1.1(0.5-2.8)$ & $16 / 57$ & $2.1(1.1-4.0)$ \\
\hline Cardiovascular diseases & $0 / 7$ & $-^{\mathrm{a}}$ & $2 / 23$ & $0.5(0.1-2.0)$ & $18 / 82$ & $1.2(0.7-2.0)$ & $53 / 165$ & $1.7(1.2-2.5)$ & $73 / 277$ & $1.4(1.0-1.8)$ \\
\hline $\begin{array}{l}\text { Symptoms and signs not } \\
\text { elsewhere classified } \\
\text { Adult-onset females }\end{array}$ & $1 / 1$ & $-^{\mathrm{a}}$ & $2 / 2$ & $9.3(0.8-102.9)$ & $5 / 14$ & $2.2(0.7-6.8)$ & $12 / 23$ & $2.6(1.1-6.5)$ & $20 / 40$ & $2.9(1.5-5.7)$ \\
\hline Cancer & $14 / 10$ & $7.3(3.2-17.0)$ & $22 / 18$ & $8.2(4.0-16.6)$ & $18 / 53$ & $2.6(1.4-4.7)$ & $31 / 85$ & $2.8(1.7-4.5)$ & $85 / 166$ & $3.8(2.8-5.2)$ \\
\hline $\begin{array}{l}\text { Endocrine, nutritional, } \\
\text { and metabolic diseases }\end{array}$ & $8 / 0$ & $-^{a}$ & $3 / 3$ & $4.9(0.8-31.4)$ & $11 / 2$ & $42.7(5.5-333.6)$ & $13 / 16$ & $5.8(2.4-14.2)$ & $35 / 21$ & $12.2(6.1-24.1)$ \\
\hline $\begin{array}{l}\text { Diseases of the } \\
\text { circulatory system: }\end{array}$ & $4 / 2$ & $18.4(2.0-164.6)$ & $6 / 9$ & $4.8(1.4-16.0)$ & $15 / 35$ & $3.2(1.6-6.4)$ & $44 / 169$ & $2.4(1.6-3.6)$ & $69 / 215$ & $2.9(2.1-4.0)$ \\
\hline $\begin{array}{l}\text { Cerebrovascular } \\
\text { diseases }\end{array}$ & $1 / 2$ & $4.5(0.3-71.8)$ & $3 / 2$ & $15.0(1.6-144.2)$ & $1 / 14$ & $0.6(0.1-5.2)$ & $9 / 37$ & $2.2(0.9-5.3)$ & $14 / 55$ & $2.4(1.2-4.7)$ \\
\hline Cardiovascular diseases & $3 / 0$ & $-{ }^{a}$ & $3 / 7$ & $2.5(0.5-11.8)$ & $14 / 21$ & $4.7(2.1-10.2)$ & $35 / 132$ & $2.5(1.6-3.8)$ & $55 / 160$ & $3.0(2.1-4.4)$ \\
\hline $\begin{array}{l}\text { Symptoms and signs not } \\
\text { elsewhere classified }\end{array}$ & $0 / 0$ & $-^{a}$ & $0 / 2$ & ${ }^{\mathrm{a}}$ & $1 / 7$ & $0.9(0.1-7.4)$ & $9 / 18$ & $5.1(1.8-14.7)$ & $10 / 27$ & $3.0(1.3-7.1)$ \\
\hline
\end{tabular}

${ }^{a}$ Due to few informative strata, statistical analysis was not possible. 
In both of these and in cancer, we identified a significantly increased mortality for both genders and all age groups in AO GHD. For both genders, cancer mortality decreased with increasing age $(P<0.05)$. Mortality from endocrine diseases was significantly increased for both genders in the two oldest age groups.

\section{Gender-specific analysis}

To identify a possible impact of gender on the causespecific mortality, all chapters were analyzed comparing male and female AO GHD patients. In this analysis, controls were not included. Female patients had a significantly increased mortality in endocrine (HR 2.2 (1.3-3.9)) and digestive diseases (HR 5.4 (1.5-19.4)); in all other chapters, no significant difference was identified.

\section{Subgroup analysis}

Analyzing only the CO GHD patients, mortality was significantly increased in craniopharyngeoma (9 deaths/48 patients) when compared with idiopathic GHD (0 deaths/ 54 patients), but not with all other CO patients (48 deaths/438 patients; HR 1.8, CI 0.8-3.9). Due to very few informative cases, we were not able to analyze the impact of GH treatment. We excluded all patients with a malignant or possibly malignant cause of GHD; hereby, the number of deaths due to cancer was reduced from 43 to 7 in patients and from 11 to 9 in controls. However, the mortality in cancer was still significantly increased.

We identified total mortality in all AO patients ever treated with GH. Mortality was comparable with controls for males (HR $1.1(0.6-2.0)$ ), but elevated for females (HR 3.3 (1.3-8.2)). Mortality was calculated in all patients with a malignant or possibly malignant cause of GHD, here the HR was 7.7 (4.2-14.2) for males and $22.7(8.7-59.5)$ for females.

Cause-specific mortality was calculated for three different subgroups: excluding all patients with a malignant or possibly malignant cause of GHD and craniopharyngeoma; excluding all patients with former acromegaly or Cushing's syndrome; and excluding all patients who received irradiation as well as their controls. All calculations were repeated corresponding to Table 4 (data not shown). All significant HRs remained significantly elevated, including the HR for cancer.

\section{Discussion}

The main result from the present study is the overall increased mortality in GHD patients when compared with age- and gender-matched controls, present in all four subgroups and all age groups among AO GHD. Furthermore, female patients had a significantly increased total mortality when compared with males in all age groups. In addition, patients with $\mathrm{CO}$ GHD had a significantly increased mortality when compared with patients with AO GHD. The increased mortality was mainly due to cancer in $\mathrm{CO}$ GHD and cancer and circulatory diseases in AO GHD.

AO GHD female patients had a significantly increased total mortality when compared with male patients. The course of risk of mortality was strikingly different between females and males, as seen in the KaplanMeier plots. We found an increased mortality in male patients within 3-4 years after entry when compared with their controls; thereafter, the curves showed a parallel course. This corresponded to a normal mortality among male patients, provided that they were alive 3-4 years after entry. In females, the two curves are diverging throughout the observation period. This implies that the relative mortality in female patients is perpetually increasing, but not that the absolute mortality is necessarily increased in comparison with male patients. We hypothesize that the divergent course of mortality may be due to loss of the normally positive effect of female gender on mortality, which may be especially prevalent early in life. It is important to keep in mind that a significantly higher percentage of AO males when compared with females (both $<55$ years of age at entry) were substituted on the sex hormone axis, and this may explain the increased total as well as the increased circulatory mortality among AO female patients. This perspective may also be relevant in relation to the gender-related differences identified in endocrine diseases. The increased mortality in females is found in other chronic diseases such as type 2 diabetes mellitus (17). The finding merits further investigation.

Among patients with $\mathrm{CO}$ GHD, cancer was the most important cause of death. The increased HRs remained significant after exclusion of high-risk patients. The number of deaths due to cancer was reduced in patients (from 34 to 7) and controls (from 11 to 9), when excluding possibly malignant causes of GHD, indicating that the malignancy per se causes the increased mortality in cancer. This is comparable with earlier findings of an increased mortality from recurrence of tumors in children in general (18), and with increased cancer mortality in children treated with recombinant hGH (9). However, it must be appreciated that these findings are based on rather different populations of patients. To our knowledge, our data are the only ones focusing on the entire population of children with GHD. In a sub-analysis, we could not discern any impact of isolated GHD on mortality in $\mathrm{CO}$ patients. However, it must be appreciated that the possible consequences of isolated GHD in a child theoretically take decades to develop, thus an eventual difference may only be identified years from now.

The majority of deaths in AO GHD were due to cancer or circulatory causes. Regarding cancer, the increased 
mortality is in accordance with the previous findings in hypopituitary patients $(2,19)$ and, here, was also found after exclusion of patients with malignant cancer prior to the GHD diagnosis. We described a skewed distribution of the causal disease in this cohort, with significantly more males than females having a diagnosis of non-functioning adenoma or other adenomas. An increased incidence of neoplasias has been described among males, but not among females diagnosed with non-functioning adenomas when compared with the background population (20). Although the two studies are not directly comparable, there is little reason to believe that the skewed distribution explained the differences in mortality. We also identified an increased mortality due to circulatory diseases, corroborating some earlier data $(1,3,4)$, whereas one study showed a significant reduction of circulatory mortality in females and a normal mortality in males (21). The latter finding was explained by a relatively lower percentage of irradiated patients when compared with the other studies. However, in the present study, the percentage of patients receiving irradiation was even lower; therefore, we hypothesize that the increased circulatory mortality was a direct consequence of abnormal cardiovascular status in these patients. As mentioned previously, a significantly higher percentage of AO males compared with females (both $<55$ years of age at entry) were substituted on the sex hormone axis, which may explain the increased mortality due to circulatory diseases among AO female patients. Interestingly, in patients over 55 years of age at entry, the HR for circulatory diseases was not statistically different in females when compared with males. It is important to stress that the highly increased HRs in the younger age groups of females when compared with males with AO GHD in circulatory diseases could not explain the increased overall mortality in females when compared with males as these calculations were based on very few deaths. In the background population, circulatory mortality is increasing with age, and it could be speculated that the relative lack of $\mathrm{GH}$ and sex hormones in the elder background population explained the findings of increased circulatory deaths. This phenomenon was accentuated among males with GHD as an (insignificantly) increasing HR with age was found, whereas for females a significant decrease was found. Interestingly, mortality was not significantly increased in GH-substituted AO males. However, in this analysis, the number of patients is limited, and no considerations are taken as to all other clinical characteristics of these patients. Generally, the interpretation of the present data, especially of strata containing a limited number of deaths, with wide CIs, should be made with caution.

We have thus identified a highly increased mortality in GHD patients. The present study does not explain whether the increased mortality in GHD was due to the causal disease, the treatment thereof, the treatment or lack of treatment of the hormonal disturbances, or possible differences in lifestyle following GHD. Therefore, a conclusion on the impact of GHD per se on mortality is not feasible. However, there is little doubt that the primary cause of GHD, for instance cancer or Cushing's disease (22), irradiation (23), and the hypopituitarism with deficits per se, increases the mortality rate. However, it is important to stress that we found an increased mortality even after exclusion of highrisk patients with malignant diseases, acromegaly, Cushing's syndrome, and craniopharyngeoma.

We included patients with a formal diagnosis of GHD as well as patients without GH-stimulation tests. This was necessary because the definition of GHD and the inclination to perform a GH-stimulation test have changed with time. Nevertheless, all patients have a highly increased risk of GHD and are considered representative of a 'true' GHD cohort. It is important to emphasize that we present data on mortality in GHD patients regardless of substitution with $\mathrm{GH}$ or sex steroids unless specified differently.

The merits of the present study are the relative magnitude and completeness. We consider the distinctions in onset of disease, i.e. CO versus AO, relevant and important, as found in other studies (24). This is the first nationwide study undertaken to analyze mortality in GHD patients, identifying patients at university hospitals as well as peripheral hospitals. The matching of the patients and controls ensures results where changes in mortality both over time and with increasing age are accounted for. Furthermore, CDR is a register with a high validity; data are almost complete and derived from various sources (25). Recently, a study evaluated the completeness and validity concerning childhood CNS tumors (26). Completeness was $98-99 \%$, and $5 \%$ of diagnoses were outside the main diagnostic groups.

In conclusion, in this population-based study we found a significantly increased mortality in GHD patients when compared with controls matched for age and gender, possibly due to their hypopituitarism. We found an increased mortality in AO females in total and in all age groups when compared with males. Both genders with CO GHD had an increased HR in cancer. In AO GHD, the main cause-specific findings were a significantly increased HR due to cancer and circulatory diseases. Whether GH supplementation or optimized substitution of other axes can modify the increased mortality remains to be clarified.

\section{Acknowledgements}

All departments with patients registered are gratefully thanked for their positive attitude towards the project. Kirstine Stochholm was supported by an unrestricted research grant from Novo Nordisk A/S, Denmark. 


\section{References}

1 Rosen T \& Bengtsson BA. Premature mortality due to cardiovascular disease in hypopituitarism. Lancet 1990336 285-288.

2 Bates AS, Van't Hoff W, Jones PJ \& Clayton RN. The effect of hypopituitarism on life expectancy. Journal of Clinical Endocrinology and Metabolism $1996 \mathbf{8 1} 1169-1172$.

3 Bulow B, Hagmar L, Mikoczy Z, Nordstrom CH \& Erfurth EM. Increased cerebrovascular mortality in patients with hypopituitarism. Clinical Endocrinology $1997 \mathbf{4 6}$ 75-81.

4 Tomlinson JW, Holden N, Hills RK, Wheatley K, Clayton RN, Bates AS, Sheppard MC \& Stewart PM. Association between premature mortality and hypopituitarism. West Midlands Prospective Hypopituitary Study Group. Lancet 2001357 425-431.

5 Svensson J, Bengtsson BA, Rosen T, Oden A \& Johannsson G. Malignant disease and cardiovascular morbidity in hypopituitary adults with or without growth hormone replacement therapy. Journal of Clinical Endocrinology and Metabolism 2004 89 3306-3312.

6 Nilsson B, Gustavsson-Kadaka E, Bengtsson BA \& Jonsson B. Pituitary adenomas in Sweden between 1958 and 1991: incidence, survival, and mortality. Journal of Clinical Endocrinology and Metabolism 200085 1420-1425.

7 Besson A, Salemi S, Gallati S, Jenal A, Horn R, Mullis PS \& Mullis PE. Reduced longevity in untreated patients with isolated growth hormone deficiency. Journal of Clinical Endocrinology and Metabolism $2003 \mathbf{8 8}$ 3664-3667.

8 Taback SP \& Dean HJ. Mortality in Canadian children with growth hormone (GH) deficiency receiving GH therapy 1967-1992. The Canadian Growth Hormone Advisory Committee. Journal of Clinical Endocrinology and Metabolism 199681 1693-1696.

9 Swerdlow AJ, Higgins CD, Adlard P \& Preece MA. Risk of cancer in patients treated with human pituitary growth hormone in the UK, 1959-85: a cohort study. Lancet $2002360273-277$.

10 Johannsson G, Bjarnason R, Bramnert M, Carlsson LM, Degerblad M, Manhem P, Rosen T, Thoren M \& Bengtsson BA. The individual responsiveness to growth hormone $(\mathrm{GH})$ treatment in $\mathrm{GH}$-deficient adults is dependent on the level of GH-binding protein, body mass index, age, and gender. Journal of Clinical Endocrinology and Metabolism 199681 1575-1581.

11 Stochholm K, Gravholt CH, Laursen T, Jorgensen JO, Laurberg P, Andersen M, Kristensen LØ, Feldt-Rasmussen U, Christiansen JS, Frydenberg M \& Green A. Incidence of growth hormone deficiency - a nationwide study. European Journal of Endocrinology 2006155 61-71.

12 Growth Hormone Research Society. Consensus guidelines for the diagnosis and treatment of growth hormone $(\mathrm{GH})$ deficiency in childhood and adolescence: summary statement of the $\mathrm{GH}$ Research Society. Journal of Clinical Endocrinology and Metabolism 200085 3990-3993.

13 Sonksen PH \& Christiansen JS. Consensus guidelines for the diagnosis and treatment of adults with growth hormone deficiency. Growth Hormone Research Society. Growth Hormone and IGF Research $1998 \mathbf{8}$ B89-B92.

14 Hartman ML, Crowe BJ, Biller BM, Ho KK, Clemmons DR \& Chipman JJ. Which patients do not require a GH stimulation test for the diagnosis of adult GH deficiency? Journal of Clinical Endocrinology and Metabolism 200287 477-485.
15 Littley MD, Shalet SM, Beardwell CG, Ahmed SR, Applegate G \& Sutton ML. Hypopituitarism following external radiotherapy for pituitary tumours in adults. Quarterly Journal of Medicine 198970 145-160.

16 Christensen SE, Jorgensen OL, Moller N \& Orskov H. Characterization of growth hormone release in response to external heating. Comparison to exercise induced release. Acta Endocrinologica 1984 107 295-301.

17 Kanaya AM, Grady D \& Barrett-Connor E. Explaining the sex difference in coronary heart disease mortality among patients with type 2 diabetes mellitus: a meta-analysis. Archives of Internal Medicine 2002162 1737-1745.

18 Neglia JP, Friedman DL, Yasui Y, Mertens AC, Hammond S, Stovall M, Donaldson SS, Meadows AT \& Robison LL. Second malignant neoplasms in five-year survivors of childhood cancer: Childhood Cancer Survivor Study. Journal of the National Cancer Institute $200193618-629$.

19 Brada M, Ford D, Ashley S, Bliss JM, Culler MD, Mason M, Rajan B \& Traish D. Risk of second brain tumour after conservative surgery and radiotherapy for pituitary adenoma. BMJ 1992304 1343-1346.

20 Popovic V, Damjanovic S, Micic D, Nesovic M, Djurovic M, Petakov M, Obradovic S, Zoric S, Simic M, Penezic Z \& Marinkovic J. Increased incidence of neoplasia in patients with pituitary adenomas. The Pituitary Study Group. Clinical Endocrinology $1998 \mathbf{4 9} 441-445$.

21 Bates AS, Bullivant B, Sheppard MC \& Stewart PM. Life expectancy following surgery for pituitary tumours. Clinical Endocrinology $199950315-319$.

22 Etxabe J \& Vazquez JA. Morbidity and mortality in Cushing'sdisease: an epidemiologic approach. Clinical Endocrinology 1994 40 479-484.

23 Erfurth EM, Bulow B, Nordstrom CH, Mikoczy Z, Hagmar L \& Stromberg U. Doubled mortality rate in irradiated patients reoperated for regrowth of a macroadenoma of the pituitary gland. European Journal of Endocrinology 2004150 497-502.

24 Attanasio AF, Lamberts SW, Matranga AM, Birkett MA, Bates PC Valk NK, Hilsted J, Bengtsson BA \& Strasburger CJ. Adult growth hormone (GH)-deficient patients demonstrate heterogeneity between childhood onset and adult onset before and during human GH treatment. Adult Growth Hormone Deficiency Study Group. Journal of Clinical Endocrinology and Metabolism $1997 \mathbf{8 2}$ $82-88$.

25 Juel K \& Helweg-Larsen K. The Danish registers of causes of death. Danish Medical Bulletin 199946 354-357.

26 Thorsteinsson R, Sorensen M, Jensen TL, Bernhardtsen TM, Gjerris F, Carstensen H, Schmiegelow K \& Raaschou-Nielsen O. Central nervous system tumours in children. An evaluation of the completeness and validity of the Cancer Registry. Ugeskrift for Laeger $20051673782-3785$.

Received 7 January 2007

Accepted 20 March 2007 